\title{
Investigating the Care Needs of those with Endometriosis: Are we listening to the
}

\section{Patients?}

Short running title: Unmet Needs in Endometriosis

Emma STEELE ${ }^{1}$, Deborah BUSH ${ }^{2,3}$, Martin HEALEY'; Charlene M RAPSEY ${ }^{4}$, Michelle PEATE ${ }^{1, *}$, Jane E GIRLING1,5,*

-

${ }^{1}$ Department of Obstetrics and Gynaecology, Royal Women's Hospital, University of Melbourne,

Australia

${ }^{2}$ Endometriosis New Zealand, Christchurch, New Zealand

${ }^{3}$ Oxford Women's Health, Christchurch; Ascot Hospital, Auckland; Auckland Gynae Group, Auckland.

${ }^{4}$ Department of Psychological Medicine, University of Otago, New Zealand

${ }^{5}$ Department of Anatomy, University of Otago, New Zealand

*shared senior author

Emma Steele: Research Assistant; emma.steele@unimelb.edu.au; ORCID ID: 0000-0003-2680-3840;

Twitter handle: @emsteele

Deborah Bush: CEO, Endometriosis New Zealand; deborah@nzendo.org.au; Twitter handle:

@DeborahBush_NZ

Martin Healey: Associate professor and gynaecologist; m.healey@unimelb.edu.au; ORCID ID: 00000003-2832-4747.

Charlene M Rapsey: Lecturer and Registered Clinical Psychologist; charlene.rapsey@otago.ac.nz;

ORCID ID: 0000-0002-1052-249X; Twitter handle: @charlene_rapsey

Michelle Peate: Senior Research Fellow; mpeate@unimelb.edu.au; ORCID ID: 0000-0003-2903-4688;

Twitter handle: @DrPeate

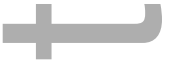

Corresponding Author:

Jane Girling

Lecturer

Department of Anatomy

University of Otago

This is the author manuscript accepted for publication and has undergone full peer review but has not been through the copyediting, typesetting, pagination and proofreading process, which may lead to differences between this version and the Version of Record. Please cite this article as doi: $10.1111 / \mathrm{AJ} 0.13080$

This article is protected by copyright. All rights reserved 
Dunedin 9016

New Zealand

Email: jane.girling@otago.ac.nz

Phone: +64 34797346

ORCID: https://orcid.org/0000-0002-8154-2068

Twitter handle: @DrJaneGirling

\section{Financial and Material Support}

JG, MP and ES would like to acknowledge the project funding from Endometriosis Australia that allowed them to initiate the work on unmet needs. MP is supported by a University of Melbourne MDHS fellowship.

\section{Conflict of Interest}

DB is a trustee on the World Endometriosis Society (WES) Board and is Founding Principal of the World Endometriosis Organisations (WEO). JG is a member of the Endometriosis Special Interest Group, Endometriosis New Zealand. ES, CMR, MH and MP have nothing to declare.

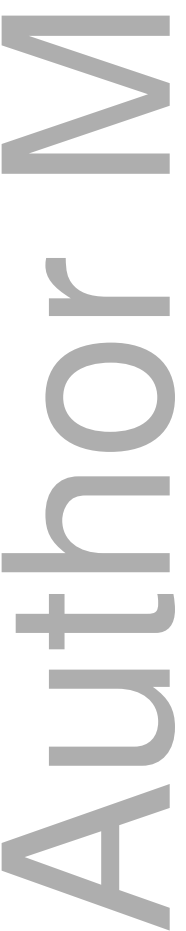

This article is protected by copyright. All rights reserved 


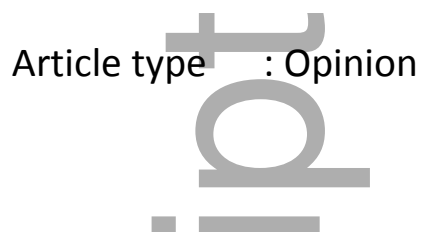

Investigating the Care Needs of those with Endometriosis: Are we listening to the Patients?

Short running title: Unmet needs in Endometriosis

Keywords: endometriosis, unmet needs, quality of life, women's health, pelvic pain.

Manuscript word count: 1267

Abstract word count: 61

Figure count: 0

Table count: 0

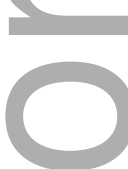

Abstract:

What do women with endometriosis need? What are the things that would make their lives easier? Where are the gaps in their care? Questions like these can only be answered by women themselves. The development of an unmet needs survey for women with endometriosis would facilitate the design of patient-centred interventions to meet these needs and ultimately improve quality of life.

Tweetable abstract:

This article is protected by copyright. All rights reserved 
What do women with \#endometriosis need to improve their \#wellbeing? Measuring and meeting unmet needs could have a profound impact on quality of life and physical and psychological wellbeing. \#QoL

\section{Introduction}

Endometriosis is a chronic, inflammatory condition characterised by endometrial-like tissue outside the uterus. ${ }^{1}$ Population prevalence is difficult to determine, but most recently it has been estimated that 1 in 9 (11\%) of Australian women born in 1973-78 had been diagnosed with endometriosis by age 40-44ㄹ not forgetting that endometriosis can also impact transgender men and other nonbinary individuals. Endometriosis symptoms are heterogeneous; the most common include pelvic pain; usually dysmenorrhea. Further, endometriosis is associated with fatigue, cyclic leg pain, back pain, pain during sexual activity, gastrointestinal upset, migraine headache, fertility issues, and can trigger the development of a chronic pain syndrome. ${ }^{1}$ There are a number of medical and surgical treatment options available for reducing pain and improving fertility in women with endometriosis. ${ }^{3}$ However, results are variable and recurrence is common. ${ }^{1}$ Many women (76\%) use self-care techniques or complementary therapies to help cope with the condition ${ }^{4}$, yet there is a paucity of high-level evidence around their efficacy. ${ }^{2}$ Despite advances in surgical, medical, and complementary therapies, endometriosis can result in persistent symptoms, with life-long implications for psychosocial health and quality of life for women with the condition and those close to them. ${ }^{5}$

The symptoms, disease progression, diagnostic process, and treatments available for endometriosis can all negatively influence the psychological and social wellbeing of women. Pelvic pain due to endometriosis can interfere with multiple domains including work, schooling, study, exercise, socialising, and sexual relationships. ${ }^{6}$ Fertility problems can cause psychological, relationship and financial issues for women and their families. ${ }^{7}$ Health-related quality of life studies in endometriosis consistently report poorer quality of life, specifically in the domains of pain, psychological function, and social function. ${ }^{8}$ The financial burden of endometriosis is also substantial at an individual and population level, with the total economic impact of endometriosis in Australia estimated to be AUD\$7.4billion for the 2018 financial year (based on an estimated population prevalence of 10\%); equivalent data are not available for New Zealand. The combination of chronic symptoms, problems with fertility, and the stigmatised nature of menstrual disorders means that endometriosis has a major impact at individual, family and societal levels - efforts to reduce this impact must be 
prioritised.

\section{Patient-Centred Care in Endometriosis}

The development of patient-centred care initiatives in endometriosis is very important, as clinical treatment alone will never completely ease the burden of this disease. The ability to capture and quantify patient-reported information is a vital step in identifying priority areas for the design of targeted interventions that deliver holistic and patient-centred care. There are a number of patientreported outcome measures currently used in endometriosis research. The majority of these are quality of life (QOL) measures. A recent systematic review of QOL measures in endometriosis found that, of the multiple generic and disease-specific measures available, the SF-36 (generic) and EHP-30 (disease-specific) were the most commonly used and best performing in terms of validity, responsiveness, reproducibility and reliability. ${ }^{10}$ Patient reported outcome measures have also been used to assess patient-centred care (e.g., EndoCare) $)^{11}$, cost (e.g., EndoCOST) ${ }^{12}$, treatment satisfaction (e.g., Endometriosis Treatment Satisfaction Questionnaire) ${ }^{13}$ and sexual difficulties (e.g., Female Sexual Function Index $)^{14}$. Importantly, the vast majority of patient reported outcome measures used in endometriosis research measure the impact that endometriosis has on various aspects of life, rather than exploring what affected individuals need to improve their wellbeing.

\section{Developing an Unmet Needs Survey for Endometriosis relevant for Australia and Aotearoa New}

\section{Zealand}

Unmet needs surveys are used to measure the aspects of care patients feel they need help with, and the extent to which those needs are being met. ${ }^{15}$ This type of survey has been used extensively in cancer care, with multiple instruments developed and validated in populations with different types and stages of cancer. ${ }^{16}$ Unmet needs surveys have also been developed for chronic conditions such as heart failure and multiple sclerosis. ${ }^{17,18}$ Studies in cancer populations have found associations between high unmet needs and reduced quality of life. Furthermore, designing and delivering interventions that meet areas of identified need results in more patient-centred care and improved quality of life. ${ }^{16}$ Given the chronic and unpredictable nature of endometriosis, and its impact on quality of life, it is reasonable to assume that women with endometriosis may have high unmet needs. We are in the process of developing such a tool as currently there is no unmet needs survey available for women with endometriosis or any other benign gynaecological condition. 
Although there are multiple unmet needs surveys in use for other conditions, it would not be appropriate to adapt an existing measure for use in endometriosis. Individuals with endometriosis are likely to have significantly different needs to those with cancer, for example, and the use of an adapted measure would have the potential to provide misleading results and may omit some needs entirely. A systematic approach to develop and validate an unmet needs survey has previously been defined, and this approach allows for flexibility in developing a survey amongst different populations where needs may vary. ${ }^{19,20}$ Qualitative research that canvasses a breadth of experiences is the foundation for survey development, as differences in symptoms, age, location, health literacy, culture and language may elicit different needs. This evidence is combined with input from experts in the field and the results of a comprehensive literature review to develop the survey instrument. A process of psychometric evaluation is then undertaken to provide evidence that the instrument is valid, reliable, and acceptable in a given population. The differences between unmet needs surveys developed for different populations show that, when developing an instrument for a new population, a systematic approach that includes exploratory qualitative research is essential. ${ }^{20}$ Such an approach would be beneficial in the development of an unmet needs survey suitable for patients with endometriosis.

In order to identify needs to be included in an unmet needs survey for women with endometriosis, a qualitative approach is the most appropriate first step. ${ }^{19} \mathrm{~A}$ recent review of qualitative research on unmet needs in endometriosis found that, although there are multiple studies exploring the impact of the condition, there are none that specifically address unmet needs. ${ }^{21}$ In order to produce a survey instrument that is applicable to a diverse population, it will be necessary to undertake qualitative research that encompasses different cultures, ages, severity of symptoms and access to healthcare to ensure that as many potential needs as possible are captured. This research will guide decisions around whether a standardised instrument can be developed, or whether multiple instruments or additional modules with question items relevant to particular sub-populations are required.

The development of an unmet needs survey for women with endometriosis will improve our understanding of this condition from the patient perspective and drive health care improvements across a number of levels. At an individual level, the survey could be used to improve patientclinician communication and guide clinical, multidisciplinary and supportive care. At a health-service level, aggregated data could be used for quality assurance activities, evaluation of interventions and development of clinical guidelines and patient information (such as decision aids). At a population 
level, the data could be used to identify state or national trends and inform health policy. The development of the survey as an online tool would allow for wide dissemination and resourceefficient data collection.

\section{Conclusion}

In recent years, endometriosis has well and truly broken into the political and public consciousness, at least in Australia, resulting in national efforts to improve the awareness, understanding, treatment and research of this disease. ${ }^{20,21}$ Patient-centred care initiatives must always be developed from a sound evidence base. An unmet needs survey for endometriosis would allow clinicians and researchers to directly ask women what they need to better cope with the condition. This information could then be used to target patient-centred interventions to meet these needs and ultimately improve quality of life.

\section{References}

1. Zondervan KT, Becker CM, Koga K, Missmer SA, Taylor RN, Vigano P. Endometriosis. Nat Rev Dis Primers. 2018;4(1):9.

2. Australian Institute of Health and Welfare. Endometriosis in Australia: prevalence and hospitalisations. 2019: Cat. no. PHE 247. Canberra: AlHW.

3. Brown J, Farquhar C. Endometriosis: an overview of Cochrane Reviews. Cochrane Database of Syst Rev. 2014(3).

4. Armour M, Sinclair J, Chalmers KJ, Smith CA. Self-management strategies amongst Australian women with endometriosis: a national online survey. BMC Complement Altern Med. 2019;19(1):17.

5. Young K, Fisher J, Kirkman M. Women's experiences of endometriosis: a systematic review and synthesis of qualitative research. J Fam Plan Reprod Health Care 2015;41:225-234.

6. Aerts L, Grangier L, Streuli I, Dallenbach P, Marci R, Wenger JM, et al. Psychosocial impact of endometriosis: From co-morbidity to intervention. Best Pract Res Clin Obstet Gynaecol. 2018;50:2-10.

7. Giudice LC, Kao LC. Endometriosis. Lancet. 2004;364(9447):1789-99.

8. Jia S-Z, Leng J-H, Shi J-H, Sun P-R, Lang J-H. Health-related quality of life in women with endometriosis: a systematic review. J Ovarian Res. 2012;5(1):29-. 
9. Ernst and Young. Sydney: The Cost of Endometriosis in Australia - A Report for EndoActive 2019.; c2019 [Cited 2019 July 1]. Available from: https://endoactive.org.au/wpcontent/uploads/29May2019-FINAL-The-Cost-of-Endometriosis-in-Australia-EY-EndoActiveReport.pdf.

10. Bourdel N, Chauvet P, Billone V, Douridas G, Fauconnier A, Gerbaud L, et al. Systematic review of quality of life measures in patients with endometriosis. PLoS One. 2019;14(1):e0208464.

11. Dancet EA, Ameye L, Sermeus W, Welkenhuysen M, Nelen WL, Tully L, et al. The ENDOCARE questionnaire (ECQ): a valid and reliable instrument to measure the patient-centeredness of endometriosis care in Europe. Hum Reprod. 2011;26(11):2988-99.

12. Simoens S, Hummelshoj L, Dunselman G, Brandes I, Dirksen C, D'Hooghe T. Endometriosis cost assessment (the EndoCost study): a cost-of-illness study protocol. Gynecol Obstet Invest. 2011;71(3):170-6.

13. Deal L, Williams VSL, DiBenedetti D, Fehnel S. Development and psychometric evaluation of the Endometriosis Treatment Satisfaction Questionnaire. Qual Life Res. 2010;19(6):899-905.

14. Melis I, Litta P, Nappi L, Agus M, Melis GB, Angioni S. Sexual function in women with deep endometriosis: Correlation with quality of life, intensity of pain, depression, anxiety, and body image. Int J Sex Health. 2015;27(2):175-85.

15. Harrison JD, Young JM, Price MA, Butow PN, Solomon MJ. What are the unmet supportive care needs of people with cancer? A systematic review. Support Care Cancer. 2009:17(8):1117-1128.

16. Tian L, Cao X, Feng X. Evaluation of psychometric properties of needs assessment tools in cancer patients: A systematic literature review. PLoS One. 2019;14(01):1-20.

17. Kersten P, McLellan DL, Gross Paju K, Grigoriadis N, Bencivenga R, Beneton C, et al. A questionnaire assessment of unmet needs for rehabilitation services and resources for people with multiple sclerosis: results of a pilot survey in five European countries. Needs Task group of MARCH (Multiple Sclerosis and Rehabilitation, Care and Health Services Research in Europe). Clin Rehabil. 2000;14(1):42-9.

18. Davidson PM, Cockburn J, Newton PJ. Unmet needs following hospitalization with heart failure: implications for clinical assessment and program planning. J Cardiovasc Nurs. 2008;23(6):541-6.

19. Hodgkinson K, Butow P, Hunt GE, Pendlebury S, Hobbs KM, Lo SK, et al. The development and evaluation of a measure to assess cancer survivors' unmet supportive care needs: the CaSUN (Cancer Survivors' Unmet Needs measure). Psychooncology. 2007;16(9):796-804. 
20. Campbell HS, Sanson Fisher R, Turner D, Hayward L, Wang XS, Taylor Brown J. Psychometric properties of cancer survivors' unmet needs survey. Support Care Cancer. 2011;19(2):221-30.

21. Steele E. Melbourne: EndoNeeds Phase 1: a protocol for research exploring the physical, psychological and social needs of Australian women with endometriosis [Thesis].; c2017 [cited 2019 July 1]. Available from: http://hdl.handle.net/11343/224098.

22. Commonwealth of Australia. Canberra: National Action Plan for Endometriosis.; c2018 [cited 2019 July 1]. Available from:

https://www.health.gov.au/internet/main/publishing.nsf/Content/endometriosis.

23. Endometriosis New Zealand. Christchurch: Endometriosis New Zealand Parliamentary Meeting.; c2019 [cited 2019 July 1] Available from: https://nzendo.org.nz/endonews/endometriosis-new-zealand-parliamentary-meeting/.

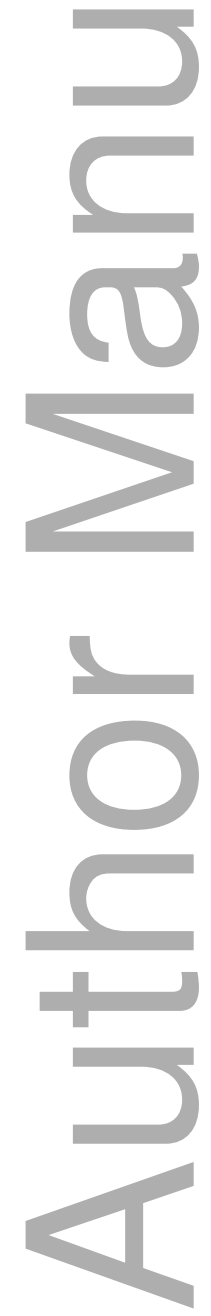




\section{University Library}

\section{- M M N E R VA A gateway to Melbourne's research publications}

Minerva Access is the Institutional Repository of The University of Melbourne

Author/s:

Steele, E;Bush, D;Healey, M;Rapsey, CM;Peate, M;Girling, JE

Title:

Investigating the care needs of those with endometriosis: Are we listening to the patients?

Date:

2019-10-16

Citation:

Steele, E., Bush, D., Healey, M., Rapsey, C. M., Peate, M. \& Girling, J. E. (2019).

Investigating the care needs of those with endometriosis: Are we listening to the patients? AUSTRALIAN \& NEW ZEALAND JOURNAL OF OBSTETRICS \& GYNAECOLOGY, 59 (6), pp.877-879. https://doi.org/10.1111/ajo.13080.

Persistent Link:

http://hdl.handle.net/11343/286506 